\title{
Medical Documentation Practice of Health Professionals and Attitude towards it at University of Gondar Hospital, Gondar, North West Ethiopia
}

\author{
Adinew Belay, Y. Narasimha Rao \\ Department of Computer Science, School of Computing \& Informatics, Mizan Tepi University, Ethiopia
}

\begin{tabular}{l}
\hline Article Info \\
\hline Article history: \\
Received Sept 25, 2016 \\
Revised Nov 11, 2016 \\
Accepted Nov 20, 2016
\end{tabular}

\section{Keyword:}

Data warehouse

Logistic regression

Medical care

Medical documentation

\begin{abstract}
Medical documentation is believed as pertinent facts of medicalcare plan. It is a warehouse for patient's information and interaction with theircaregivers in particular. However, there are lack of completeness, consistency, proper recoding and other constraints regarding the current medical recordpractice. The main objective of this study was to assess the current medicaldocumentation practice of health professionals and attitude towards it at University of Gondar Hospital, Gondar, North West Ethiopia, 2016. Institution based cross sectional quantitative study was conductedfrom March 15 to April 30, 2016 at University of Gondar Hospital. About 260 health professionals who work in different wards were participated. Data werecollected using structured self-administered questionnaires of professionals andreviewed their recorded medical documentation (chart). Logistic regressions; both bi-variable and multi-variable logistic regressions analyses models werefitted. The odds ratio with $95 \%$ CI was computed and these variables which havea ( $\mathrm{p}$-value $<0.05$ ) in the multi-variable logistic regression analysis model weretaken as statistically significant and interpreted accordingly. Good medical documentation practice by health professionals was $45.4 \%(n=118)$. Documentation for all patients using documentation standard toolswith AOR=1.799(95\%CI [1.065, 3.040]), working area with $\mathrm{AOR}=2.522(95 \% \mathrm{CI}[1.264,5.033])$, and favourable attitude towards medical documentation withadjusted $\mathrm{OR}=1.182(95 \%$ CI $[1.039,3.169])$ were significantly associated withgood medical documentation practice.Medical documentation practice at University of Gondar Hospital was found low.Documentation using standard tools, working area (setting) and attitude ofprofessionals were important factors associated with medical documentationpractice. Organizational support needs to be strengthening, ensure procedure, format and documentation type (including documentation tools and forms); etcneeds emphasis to improve documentation practice.
\end{abstract}

Copyright (c) 2016 Institute of Advanced Engineering and Science. All rights reserved.

\section{Corresponding Author:}

Adinew Belay,

Department of Computer Science, School of Computing \&Informatics,

Mizan Tepi University, Ethiopia.

\section{INTRODUCTION}

Documentation is a record of the care, the clinical assessment, professional judgment and critical thinking used by a health professional in relation to theprovision of patient care. This documentation may include written and electronichealth records, observation charts, actions, outcomes, check lists, communicationbooks, shift / management reports and clinical anecdotal notes or personal reflections (held by the clinicians personally or any other form of documentation pertaining tothe care provided. The medical documentation (medical record or paper basedrecord) therefore, is one of the health (clinical) records in which 
we need to assessits practice level or status. Of course, the practice or the documentation may berecorded or done by doctors, nurses, midwives and other care providers (health professionals) in general [1].

Despite widespread interest in standardizing of health records in many parts of theworld [2], narrative text record (manually written documentation) for patient'sinformation is a usual trend everywhere. The data in documentation can beorganized in a variety of ways including time-oriented, problem-oriented, and sourceoriented approaches. Based on a recent review, an emphasis of data attributes (accuracy, completeness, and timeliness) are needed for documentation to quality measurement [3].

Likewise the value of health records is ultimately dependent on their completeness for providing patient's information and care provision. This varies with physician topatient communication, the patient's condition and the physician's documentation style. Of course, clinical documentation (record) has been found complete andappropriate for clinical decisions when data are filled on time [4]. But, study shows that many physicians and other health care providers have argued that the quality for clinical documentation is inadequate and overloading withirrelevant data [5].

Paper-based documentation is practiced in most developing countries [6]; as an African it is a basic issue to assess this documentation practice of health professionals and related factors towards documentation. Developing counties therefore are, highly relied on standard tools, clinical guidelines, documentation books forms / formats, procedures and other resources / materials to record patient's information in hospitals and other health centers due to a very limited health professionals' practice unlike the developed world (i.e. EHR) [6]. The information in the medical documentation is definitely valuable. However, theprocess of documenting it is given less priority by many health care givers. A busy physician may accidentally record a progress note in the wrong patient's health records. Medical or clinical assessment of vital signs might be consistent, but the documentation process was highly variable within groups and among hospitals. Different health care professionals and specialties have developed their own typesof documentation style to document patient's care in the paper-based patient record system. Lack of a unified documentation approach finally leads to a national proposal to generate a unified paper-based patient record. This serves as a goodbasis for a unified national documentation style. Since, transforming the paperbased record into digital form by purely digitizing the narrative text does not yield the benefits. So, it is essential that the structure, data set headings and classifications are used as clear medical / clinical documentation guides and contents [7]. A nurse may get a call to assist a patient and forget to record medication given toanother patient [8].

Although clinical guidelines and standardized tools are essential for evidence based decision making healthcare provision and manually written documentation practice;their usability used by health professionals is low because of physician's attitude [9]. Evidence indicates that besides of their benefits for documentation practice, guidelines, documentation sheets/formats, standard tools in total were in doubt ofresistance from health professionals. Information retrieval from narrative documentsof chart or written documentation is rarely used outside laboratories where information extraction systems have been developed [10]. From all the above reviews, medical documentations (manually written documents) are the only warehouse of patient's information. But, these documentations are withmany problems and sometimes negligible for some health professionals. This is dueto variations of documentation styles and documentation standards, sheets/formatsthey used. On the other hand, data in hospitals remain incomplete and inappropriatewhile documenting, reporting, charting and etc. And thus, most records neglect thepatients' problem and practices regarding documentation in the hospital being experienced [11].

There are gaps in Ethiopian context. Because, there is no study conducted to inform whether the above mentioned standard tools are properly used to the completenessof documentation or not. Since Ethiopia is one of the developing nations, theproblem regarding patient's written record or documented information is a seriousissue from different corners. However, the level of documentation practice of health professionals, attitude stowards documentation about patient's information and even other related factors affecting documentation practice are not known indeed. Only, the federal ministry of health (FMoH) was trying to alleviate such problems by giving training for healthworkers and preparing guidelines like Ethiopian hospitals reform implementation guideline. But, no researches were done to show where the status of documentation practices and the gaps are nationally. So, it is better to focus on reducing the gaps between practice level of professionals and their attitude to documentation using evidence. On the other hand when to document, what to document, ho w todocument etc are crucial aspects to fill the gaps.

\section{EXISTING METHODS}

Medical Documentation Practice Since 2006, AMIA has organized Health Policy to examine issues concerninghealthcare and health information policy towards the generation of health records (medical documentations) that will give up the rich patients' data. This is an evidence in which medical documentations play a key role in the efforts by providing access todata that can improve individual care, organization support, 
clinical research, qualityimprovement efforts and the achievement of public health objectives; all of whichwork towards documentation system improvement(12). Study shows that health professionals have a positive perspective about documentation systems, but their 'full function' practice is low: $3.6 \%$ in 2006 to $6.9 \%$ in 2009 [12,13].

Medical record keeping has been almost fully implemented even in several developed countries including Sweden, Denmark, the Netherlands and UK althoughit has been implemented in less than $20 \%$ of US hospitals. Likewise, paper-based documentation is practiced in most developing countries [6]. Nurses in the Netherlands recorded low scores on the accuracy of the documentation of their interventions [14]. The study conducted in Jamaican based on descriptive cross sectional design, 2013 by reviewed 90 patients records of 3 wards were audited documentation practices health professionals using Jamaican Ministry of Health tool. The result shows $(97 \%, 98 \%, 96 \%$ and 98\%) percentages of records were legible, neat, and concise and followed documentation guidelines respectively. Only $26 \%$ of the records hadnursing diagnosis, which corresponded to the current medical diagnosis and $48 \%$ had documented evidence of discharge planning [15]. In Finland, paper-based patient records have been a longitudinal (continuing)collection of patient data [7]. Documentation of patients with chronic pain from the Southern health care centerregion of Stockholm results that nurses reported insufficient documentation (24\%). In Nigeria, health record Inadequacies were found in clinical documentation,especially gross under utilization of discharge summary forms. However, some formswere properly documented, suggesting that hospital health care providers possess. The necessary skills for quality clinical documentation but lack the will. When dictation or a manual system is used, the production of accurate health records depends on the providers' record keeping practices [16]. Results from 9 general hospitals of South Africa report among 459 records in 1989, 27.7\% (127) of the records were from medical units, $29.4 \%$ from surgical units, 14.6 from pediatrics units and the remaining from the general units; it shows insufficient and poorly documented practice [17].

\section{METHODOLOGY}

\subsection{Study Design}

An institution based cross sectional quantitative study was conducted in University of Gondar hospital from March 15 to April 30 2016. The study was conducted at University of Gondar Hospital, North Gondar, North West Ethiopia. The hospital was established in 1920 in Amhararegional state in North Gondar zone, North West Ethiopia, Gondar town administration 748 far from Addis Ababa. In 2016, the total number of health professionals in this hospital is about 793 who provide services for the catchment area with estimated number of populations more than five million. All health professionals who were worked at the University of Gondar Hospital during data collection period.

\subsection{The Inclusion and Exclusion Criteria}

All health professionals who were not willing, those who were on leave and those pharmacists were excluded.Sample size in this study was calculated as follows using the assumptions of single population proportion formula by the assumptions of.

$\mathrm{n}=$ sample size

$\mathrm{z}=$ standardized normal distribution value at $95 \% \mathrm{CI}$, which is 1.96

$\mathrm{p}=$ medical documentation practice $50 \%$

$\mathrm{d}=\mathrm{w}=$ the margin error, taken as $5 \%$

$\mathrm{n}=[\mathrm{Z}(\alpha / 2) 2 * \mathrm{P}(1-\mathrm{P})] / \mathrm{d} 2$

$\mathrm{n}=[(1.96) 2 * 0.5(1-0.5)] /(0.05) 2$

$\mathrm{n}=384$

Here correction factor was used (population reduction formula)

$\mathrm{n} /(1+\mathrm{n} / \mathrm{N})=384 /(1+384 / 629)$

$=240$

By assuming the non-response rate of 10\% [18] the total sample size became 264.

\subsection{Sampling Selection Procedure}

Stratified sampling procedure was used to select the respondents. Health professionals in each ward of inpatient department were randomly selected usingsimple random sampling after proportional allocation of health professionals in eachprofession and work setting was ensured. The strata were wards in which theparticipant health professionals were worked. These four strata were medical, surgical, pediatrics and obstetrics \& gynecology wards. Sampling selection procedure of health professionals from each ward at UoG hospital as shown in Figure 1. 


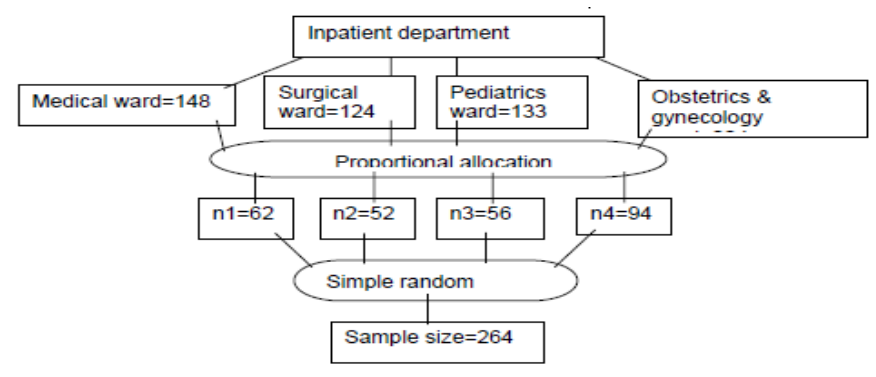

Figure 1. Sampling Selection Procedure of Health Professionals from Each ward at UoG hospital, 2016, Ethiopia $(n=260)$

\section{ETHICAL CONSIDERATIONS}

Ethical clearance was obtained from Institution of Public Health, Research Ethical Review Board of College of Medicine and Health Sciences, University of Gondar.Communication with University of Gondar Hospital administration was made throughformal letter from the clinical director and ward team leaders. The purposes and theobjectives of the study were explained in detail for the participants and hence, written informed consents were received. To keep confidentiality data collection anonymity was maintained in all aspects. Respondents were informed thatparticipation was on a voluntary basis. They were also told to refuse and withdrawany time if they feel discomfort and unwilling to participate in the study.Ethical clearance from both UoG and UoG Hospital.

\section{RESULTS}

\subsection{Socio Demographic Characteristics ff Study Participants}

Among 264 study participants, 260 (98.5) returned the questionnaire back. About118 (63 females and 55 males) were answered 'Yes' and 142 (78 females 64 males)were answered 'No' to the questions provided from the document reviewedassessment. More than half of participants $141(54.2 \%)$ were female participants,nearly half of them $128(49.2 \%)$ were single. From the total participants, $50 \%$ ofthem were below 30 years of age. About $94(36.2 \%)$ of them were worked inobstetrics and gynecology wards and most of them $231(88.8 \%)$ were Bachelordegree holders. Table 1 shows the Socio-demographic characteristics of health professionals who were worked at University of Gondar Hospital.

Table 1. Socio-Demographic Characteristics of Health Professionals Who Were Worked at University of Gondar Hospital, North West Ethiopia, 2016 (N=260)

\begin{tabular}{|c|c|c|c|}
\hline Variable & & Frequency & Percentage \\
\hline \multirow[t]{4}{*}{ Age } & $20-24$ & 15 & 5.8 \\
\hline & $25-29$ & 107 & 41.2 \\
\hline & $30-34$ & 85 & 20.4 \\
\hline & $>=35$ & & 32.7 \\
\hline \multirow[t]{2}{*}{ Sex } & Male & 141 & 54.2 \\
\hline & Female & 119 & 45.8 \\
\hline \multirow[t]{4}{*}{ Marital Status } & Single & 130 & 50 \\
\hline & Married & 116 & 44.6 \\
\hline & Divorced & 8 & 3.1 \\
\hline & Others & 6 & 2.3 \\
\hline \multirow[t]{4}{*}{ Religion } & Orthodox & 237 & 91.2 \\
\hline & Muslim & 12 & 4.8 \\
\hline & Protestant & 9 & 3.5 \\
\hline & Others & 2 & 0.8 \\
\hline \multirow[t]{5}{*}{ Working setting } & Medical & 61 & 23.5 \\
\hline & Surgical & 49 & 18.8 \\
\hline & Pediatric & 56 & 21.5 \\
\hline & Obstetrics \& & 94 & 36.2 \\
\hline & Gynecology & & \\
\hline \multirow[t]{4}{*}{ Educational status } & Diploma & 11 & 4.2 \\
\hline & Bachelor & 231 & 88.8 \\
\hline & degree & 18 & 6.9 \\
\hline & Master \& above & & \\
\hline \multirow[t]{3}{*}{ Experience } & $<5$ years & 131 & 50.4 \\
\hline & $5-10$ years & 69 & 26.5 \\
\hline & $>=10$ years & 60 & 23.1 \\
\hline
\end{tabular}

IJAAS Vol. 5, No. 4, December 2016 : 157 - 162 
In this research medical documentation practice at UoG Hospital in 2016 is (45.4\%); that means it was relatively low since documentation is a crucial aspect for patientslife. Even though the finding is too hard for comparing with other local studies, let tocompare with countries having different socio-economic status, geographical settings, life style and others. As it was mentioned, this study revealed that good medical documentation practice among health professionals was $45.4 \%$; and this is much lower as compared tostudy in Jamaica (98\%) [19]. The difference of course could be due to the research methodology, research setting. Descriptive approach was followed and only medicalward were the concern there in Jamaica but, here institutional cross sectionalquantitative approach was followed and four work setting wards were included asthe same time respectively. Another difference could be the way to follow standard documentation guidelines and procedures. Whereas, the result obtained from thisstudy is higher than the study done in Iran (22.9\%) [20]. The possible reason couldbe due to the different instrument used and the institutional structure that means organizational supervision system, responsibility and accountability of the leadersand institution.

The findings of this study were collectively obtained from $16.9 \%$ from medical wards, $16.9 \%$ from surgical ward, $20.3 \%$ from pediatrics ward and $45.8 \%$ from obstetrics and gynecology wards. This result is somewhat closer to results from 9 general hospitals of South Africa audit among 459 records in 1989, 27.7\% of the records were from medical units, 29.4\% from surgical units, 14.6 from pediatrics units and there maining from the general units. Specially, the result in this study $45.8 \%$ from obstetrics and gynecology wards were sufficient enough than results of all the unitsof South Africa. The study conducted in Jamaican in 2013 based on descriptive cross sectional design by reviewed 90 patients records were audited documentation practices of health professionals using Jamaican Ministry of Health tool. The result shows $98 \%$ of records were followed documentation guidelines and $48 \%$ had document edevidence of discharge planning [15]. But, in this study $60.8 \%$ of health professionals had followed medical documentation standard tools (sheet and guideline,procedures). This might be because of the socio-economic and cultural difference between the two countries. And the difference of tools used by ministry of health ofthe two countries. A Postal questionnaire survey between October 1993 and January 1994 was conducted at Hospitals found Oxford region and the result shows that most respondents $77 \%$ were welcoming favorable attitudes towards medical documentation standard tools [21]. This is again higher than this study's finding. Thisis most probably due to the difference of study design selected and the ways of lifestyle the participants followed. This study reveals that was significantly associated with medical documentation practice.

Those professionals who have favorable attitude about medical documentation areless likely to have good documentation practice compared to those who have unfavorable attitude. This is due to human resource shortages, less organizational support and shortage of equipment as described in Figure 4. This study is consistent with studies from Malawi [22] a mixed of quantitative and qualitativemethods was applied using checklists at the Medical Department of Kamuzu Central Hospital in Lilongwe, Malawi identified that human resource shortages, staff attitudes and shortage of equipment as big obstacles for documentation registers. From the study carried out in Nigeria in 2009, documentation performance was verygood $(98.49 \%)$ and hence the result was much higher than the findings of this study. Of course, the reason may be a study conducted in Nigeria was a retrospective study design to assess the documentation of 780 paper-based health records ofinpatients discharged. But records reviewed from the departments of obstetrics (45.9\%) [23] was consistent with the study result in our research $(45.8 \%)$.

\subsection{Limitations}

a. Self-administrator questionnaires are not the best way to collect the views ofindividual professionals about such a subject. We have no audit of therespondent's attitude and performance in MDP.

b. The study was conducted only on a single referral hospital; and thus it is notgeneralize able for other health centers (HC).

c. A broad literature search on this topic shows lack of similar published studiesin Ethiopia. Hence it was difficult to make comparisons in the Ethiopian healthprofessionals' context.

\section{CONCLUSION}

The findings of this study indicated that health professionals at hospitals have somewhat poor documentation practice and unfavorable attitude to medical documentation practice. The study confirms the importance of work setting, documenting for all patients using documentation standard tools and attitude towards medical documentations. It also shows how universal standard guidelines for care in different settings are differently used. And even, one can have favorable attitude towards medical documentation, there might lack medical documentation practice. This study findings lead to conclude that if someone had favorable focus tomedical documentation; it didn't mean that s/he had put action to medical documentation practice. This of 
course was due to different reasons such asshortage of format, lack of time, lack of space to document and high patient toprofessional ratio.

\section{REFERENCES}

[1] WHO. Guidelines for Medical Record and Clinical Documentation.SEARO. September 2007.

[2] K. Häyrinen, KHP, Nykänen. eHealth - making health care better for European citizens: An Action Plan for the European eHealth Area. 2004.

[3] Chan KS FJ, Weiner JP, "Electronic health records and the reliability and validity of quality measures: a review of the literature," MedCareRes Rev, vol. 5, pp. 503-27, 2010.

[4] Paul C. LM. and Gorden, SM., "Use of computer-based records, completeness of documentation and appropriateness of documented clinical decisions," J Am Med Inform Assoc, vol. 6(245), 1999.

[5] J. G., "Delivering the electronic healthcare record for the 21st century, " Int J Med Inf, vol. 64(2-3), pp. 111-27, 2001.

[6] Organization WH. Electronic Health Records: Manual for Developing Countries, 2006.

[7] K. Häyrinen KHP, Nykänen, "Use of headings and classifications by physicians inmedical narratives of EHRs - an evaluation study in a Finnish hospital," Applied Clinical Informatics, vol. 22(2), pp. 143-57, March 2011.

[8] EK H. Medical Record Management.9th edn. Berwyn, Illinois: Physician's Records Company. 1990:596.

[9] Ivan Sola JMCea. Attitude and perceptions about clinical guidelines: A qualitative study with spanish physicians. Aplos, vol. 9(2). February 2014.

[10] Meystre SM SGea. Extracting information from textual documents in the electronic health record: a review of recent research.Yearb Med Inform, pp. 128-44, 2008.

[11] Chapman Y. FK, "The study of nursing documentation complecxities," International journal of nursing practice, vol. 12, pp. 366-74, 2006

[12] ME G. Early glimpses of the learning health care system: the potential impact of health IT Academy Health. July 2012.

[13] Hsiao C HE, Socey TC, and Cai B. Electronic medical record/electronic health record systems of office-based physicians.National Center for Health Statistics. 2010

[14] Paans W, Sermeus, et al., "Prevalence of accurate nursing documentation in patient records," Journal of Advanced Nursing, vol. 66, pp. 2481-9, 2010.

[15] Blake-Mowatt, C., "Evaluation of registered nurses' knowledge and practice of documentation at a Jamaican hospital," International Nursing Review, vol. 60, pp. 328-34, 2013.

[16] Cora AC DG, Chand D., "Understanding the work of medical transcriptionists in the production of medical records," Health Informatics Journal, vol. 16, pp. 87-100, 2010.

[17] LR.Uys. Standards for Nursing Documentation in General Hospital in South Africa, pp. 12. July 1989.

[18] Piette JD, et al., "Impacts of e-health on the outcomes of care in low- and middle income countries: where do we go from here?" Bulletin of the World Health Organization, vol. 1 (90), pp. 365-72, 2012.

[19] C. Blake-Mowatt JLML, and J. Bennett, "Evaluation of registered nurses' knowledge and practice of documentation at a Jamaican hospital," International Council of Nurses, pp. 328-34. 7 June 2013.

[20] Madineh Jasemi VZ, A. Rahmani, A. Mohajjel, and F. Alsadathoseini, "Knowledge and Practice of Tabriz Teaching Hospitals' Nurses Regarding Nursing Documentation," International medical journal. Oct 29, 2012.

[21] Mansfield CD., "Attitudes and behaviours towards clinical guidelines," The clinicians'perspective, vol. 4, pp. 250-5, 1995. [Online]. Available: group.bmj.com.

[22] al. A-De. Understanding the barriers to setting up a healthcare quality improvement process in resource-limited settings: a situational analysis at the Medical Department of Kamuzu Central Hospital in Lilongwe, BMC Health Services Research. Malawi, 2014.

[23] Ibrahim Taiwo AO, Kayode Abiodun, et al., "Data quality assessment in healthcare: a365-day chart review of inpatients' health records at a Nigerian tertiary hospital," J Am MedInform Assoc., vol. 19, pp. 1039-42. 14 July 2012. 